\title{
A Meta-Analysis of the Relationship between Information and Communications Technology and Academic Achievement in Iran
}

\author{
Hossein Najafi ${ }^{1}$, Mohammad Jafar Rezaei ${ }^{2}$, Mohammad Ali Javadi Boura ${ }^{3}$, \\ Zohre Mottagi ${ }^{4}$ \\ ${ }^{1}$ Assistant Professor, Department of Educational Sciences, Payame NoorUniversity, Iran. \\ 2.Ph.D. Student, Department of Educational Sciences, Faculty of Educational Sciences and Psychology, \\ University of Isfahan, Iran. \\ ${ }^{3}$.Assistant Professor, Farhangian University, Mazandaran,Sari, Iran. \\ 4.Ph.D. Student, Department of Educational Sciences, Faculty of Educational Sciences and Psychology, \\ University of Isfahan, Iran.
}

\begin{abstract}
The present research was to a meta-analysis of the relationship between information and communications technology (ICT) and academic achievement. The population consisted of all the research on this subject until 2013, and using systematic sampling, 18 research studies were selected as the sample. Structured review based on meta-analysis was used to answer the research questions, and Cohen's model was used to interpret the results. The results showed that the relationship between ICT and academic achievement is significant, because the effect size for this relationship was 0.581, which is above average based on Cohen's model.
\end{abstract}

Key Words: Information and communications technology, academic achievement, meta-analysis

\section{Introduction}

An important problem in the area of teaching is lack of interest in learning among students. Using multimedia and information and communications technology (ICT) in learning is one way to bring about motivation and academic achievement in students (Zameni et al., 2010). Advanced technologies, educational media, and multimedia are increasingly used in the teaching-learning process (Najafi, 2012). Research has shown that ICT-based, learner-based, interactive, cooperative, and flexible teaching along with active learning strategies motivate learners and increasing teacher-learner cooperation (Farajollahi \& Zarifsanayee, 2009) and create more learning opportunities (Mahdinejad \& Amoee, 2011). By effectively using ICT, students demonstrate their abilities and skills faster and teachers have more alternatives in creative instruction. Other important features of ICT, including computers, the Internet, and multimedia, include capacity, variety, speed, automation, contingency, interoperability, precision, and validity which are of utmost importance in learning. These features change the role of the teacher and the learner, facilitate learning, and lead to interactive learning, learner autonomy, self-sufficiency, and self-confidence (Zameni et al., 2012). By integrating content and information literacy, often in textual and visual forms, ICT produces significant learning and academic achievement (Zofan, 2007). In other words, incorporation of ICT into the area of education has changed the role of teachers from a mere source of educational material to a manager supervising the learning process. This increases self-sufficiency and self-confidence in students (Zameni et al., 2012).

In this approach, teaching is accompanied by attractive visual materials, which increases students' interest in learning. Also based on research evidence, approximately 75 percent of human learning occurs visually, while only 25 percent occurs through auditory, olfactory, tactile, and gustatory senses (Zofan, 2007). ICT is a tool that involves the visual and auditory senses of the learners and thus it deepens learning in students. Research evidence mostly supports the positive effect of ICT on learning and academic achievement (Malekyian et al., 2011; Niyazazari and Hosseini, 2012, Shekari, 2012; Zameni and Kardan, 2010; Satari et al., 2012; Ahmadi et al., 2011; Momeni et al., 2012; Soleymanpour et al., 2010). However, some studies have shown that ICT is not very effective in teaching and learning processes (Chaney, 2003; Zare, 2009).

Therefore, there is an inconsistency in research evidence on the relationship between ICT and academic achievement. Also the size of the effect of ICT on academic achievement is not clear. The present research uses a meta-analysis methodology to provide new insights into this relationship. Meta-analysis focuses on contrasting and combining the results of different studies in order to discover new relationships that cannot be otherwise obtained (Hatami, 2006). The literature on ICT and its relationship with academic achievement mostly reports the significance of the relationships, but it does not provide much evidence about the extent to 
which ICT influences learning and academic achievement (Khalkhali et al., 2011). Thus, this research tries to address the following questions:

1. Does ICT have a significant effect on academic achievement?

2. What is the size of the effect of ICT on academic achievement?

\section{Methodology}

This research uses a meta-analysis methodology. In meta-analysis, the aim is to calculate the effect size of distinct variables and combine them to obtain the mean effect size (Jamali et al., 2012). The population of the research consisted of all the Iranian research on the effect of information and communications technology (ICT) on academic achievement during the period 2003-2013 indexed in Iranian Research Institute for Information Science and Technology (IRANDOC), Science Information Database (SID), Noor Magazines ${ }^{1}$, Iran's Publications Database ${ }^{2}$, and the National Library of Iran. Overall, 94 research papers about the effect of ICT on academic achievement were obtained. Since all of the studies conducted during the period of interest were not available, 18 documents were selected as sample using systematic sampling. Effect size was manually calculated. Finally, descriptive and inferential statistics (mean standard error, standard error, variance, upper and lower limits, and z-score) and fixed and random effects meta-analysis models were used for data analysis. Also Cohen's method was used to interpret the results.

\section{Findings}

Before inferential analysis, we first describe the statistical methods used in the literature to examine the relationship between ICT and academic achievement (Table 1)

Table 1. Frequency of statistical analyses used in the sample research

\begin{tabular}{|l|l|l|}
\hline Statistical Analysis & Frequency & Percentage \\
\hline Variance and covariance analyses & 6 & $\% 34$ \\
\hline T dependent and independent & 2 & $\% 11$ \\
\hline The correlation coefficient & 3 & $\% 17$ \\
\hline Analysis of variance and T & 2 & $\% 11$ \\
\hline Correlation coefficient and T & 1 & $\% 05$ \\
\hline Independent t & 4 & $\% 22$ \\
\hline Total & 18 & $100 \%$ \\
\hline
\end{tabular}

The data provided in Table 1 show that variance and covariance analyses are most widely used in the research on ICT and academic achievement. However, to obtain more accurate information from the sample studies, these data need to be presented in the form of a meta-analysis checklist (Table 2).

Table 2. Studies that meet the criteria for inclusion in the meta-analysis

\begin{tabular}{|c|c|c|c|c|c|}
\hline$\dot{\mathbf{z}}$ & 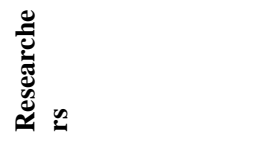 & 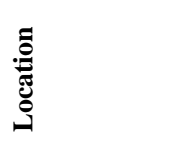 & 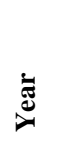 & $\stackrel{\vec{s}}{\stackrel{G}{G}}$ & 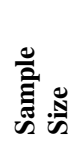 \\
\hline 1 & Malekyian et al. & Tehran & 2011 & Variance analysis & 25 \\
\hline 2 & Niyazazari\& Hosseini & Babl & 2012 & Covariance analysis & 76 \\
\hline 3 & Shekari & Kashan & 2010 & Variance analysis T dependent & 193 \\
\hline 4 & Zameni \&Karan & Mahmodabad & 2011 & T dependent & 88 \\
\hline 5 & Zameni et al. & Joybar & 2011 & $\mathrm{~T}$ dependent and independent & 40 \\
\hline 6 & Niyazazari et al. & Sari & 2012 & Covariance analysis & 217 \\
\hline 7 & Satari et al. & Heris & 2012 & The correlation coefficient & 317 \\
\hline 8 & Ahmadi et al. & Sari & 2011 & T dependent and independent & 40 \\
\hline 9 & Satari\&Mohammadi & Parsabad & 2011 & The correlation coefficient & 215 \\
\hline 10 & Solyamanpoor et al. & Ramsar & 2010 & T dependent & 50 \\
\hline 11 & Safariyan et al. & Qaemshahr & 2010 & T dependent & 60 \\
\hline 12 & Momeni et al. & Birjand & 2012 & Covariance analysis & 60 \\
\hline 13 & Zare & Rodhen & 2009 & T dependent & 160 \\
\hline 14 & Afkhami et al. & Yazd & 2012 & & 406 \\
\hline 15 & Aminifar et al. & Torkamanchay & 2012 & $\begin{array}{l}\text { Variance analysis and } \mathrm{T} \\
\text { dependent }\end{array}$ & 18 \\
\hline 16 & Najafi & Khalkhal & 2008 & Variance analysis & 150 \\
\hline 17 & Qaznavi & Khash & 2010 & Covariance analysis & 218 \\
\hline 18 & Dayinezhad et al. & Khash & 2010 & Variance analysis & 320 \\
\hline
\end{tabular}

\footnotetext{
WwW.noormags.com
}

${ }^{2}$ www.magiran.com 
1st Question: Can we decide about the relationship between ICT and academic achievement based on the meta-analysis of the relevant studies?

Effect sizes were combined to answer this question. Accordingly, effect sizes are individually estimated and then combined mixed and random effects were calculated (Table 3 ).

Table 3. Meta-analysis of the effect of ICT on academic achievement (random effects model)

\begin{tabular}{|c|c|c|c|c|c|c|c|c|}
\hline$\dot{\mathbf{z}}$ & 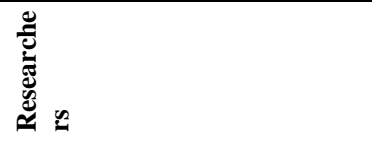 & 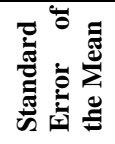 & 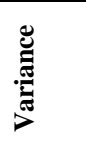 & 总 & 离泀 & 离: & $\mathbf{N}$ & $\sim$ \\
\hline 1 & Malekyian et al (2011) & 1.012 & 0.129 & 0.023 & 0.223 & 0.732 & 4.781 & 0.021 \\
\hline 2 & Niyazazari\& Hosseini(2012) & 0.432 & 0.390 & 0.034 & 0.172 & 1.021 & 0.984 & 0.032 \\
\hline 3 & Shekari(2010) & 0.598 & 0.034 & 0.035 & 0.132 & 0.909 & 11.982 & 0.012 \\
\hline 4 & Zameni \&Karan(2011) & 2.120 & 0.034 & 0.021 & 0.182 & 0.897 & 1.012 & 0.001 \\
\hline 5 & Zameni et al( 2011) & 0.108 & 0.109 & 0.102 & 0.174 & 0.827 & 2.022 & 0.007 \\
\hline 6 & Niyazazari et al( 2012) & 0.349 & 0.339 & 0.017 & 0.199 & 0.423 & 6.715 & 0.003 \\
\hline 7 & Satari et al(2012) & 0.849 & 0.435 & 0.082 & 0.042 & 0.857 & 3.301 & 0.021 \\
\hline 8 & Ahmadi et al( 2011) & 0.905 & 0.247 & 0.029 & 0.091 & 0.902 & 2.513 & 0.036 \\
\hline 9 & Satari\&Mohammadi(2011) & 0.505 & 0.190 & 0.020 & 0.117 & 0.272 & 1.369 & 0.000 \\
\hline 10 & Solyamanpoor et a( 2010) & 0.298 & 0.398 & 0.062 & 0.084 & 0.948 & 1.231 & 0.004 \\
\hline 11 & Safariyan et al(2010. & 0.127 & 0.098 & 0.098 & 0.108 & 1.072 & 1.820 & 0.002 \\
\hline 12 & Momeni et a. 2012) & 0.356 & 0.309 & 0.041 & 0.318 & 0.855 & 1.723 & 0.009 \\
\hline 13 & Zare(2009) & 0.397 & 0.275 & 0.009 & 0.392 & 0.443 & 2.290 & 0.023 \\
\hline 14 & Afkhami et al(2012) & 0.744 & 0.332 & 0.029 & 0.247 & 0.630 & 0.987 & 0.043 \\
\hline 15 & Aminifar et al (2012) & 0.188 & 0.179 & 0.167 & 0.056 & 0.716 & 2.992 & 0.012 \\
\hline 16 & Najafi(2008) & 0.577 & 0212 & 0.079 & 0.230 & 0.990 & 1.723 & 0.002 \\
\hline 17 & Qaznavi(2010) & 0.489 & 0.290 & 0.032 & 0.225 & 0.321 & 1.153 & 0.000 \\
\hline 18 & Dayinezhad et al(2010) & 0.213 & 0.412 & 0.029 & 0.024 & 0.024 & 1.024 & 0.002 \\
\hline 19 & Effects of a fixed combination & 0.584 & 0.086 & 0.001 & 0.383 & 0.621 & 10.648 & 0.000 \\
\hline 20 & $\begin{array}{l}\text { The combined effects of } \\
\text { random }\end{array}$ & 0.584 & 0.086 & 0.001 & 0.383 & 0.621 & 10.648 & 0.000 \\
\hline
\end{tabular}

Considering the random effects model and the $95 \%$ confidence interval, the data in Table 3 show that the studies of Niyazazari and Hosseini (2012), Shakeri (2012), Zameni et al. (2011), Niyazazari et al. (2012), Satari and Mohammadi (2011), Soleymanpour et al. (2010), Momeni et al. (2012), Safariyan et al. (2010), Zare (2009), Aminifar et al. (2011), Najafi (2009), and Khaznavi (2010) were significant in terms of effect size. That is because the mean effect size is about 0.6 and studies where the effect size is less than this value are considered significant. On the other hand, effect size was not significant in the studies of Malekyian et al. (2011), Zameni and Kardan (2012), Satari et al. (2010), Ahmadi et al. (2011), and Afkhami et al. (2012). In these studies the effect size is greater than the mean effect size (0.6). The results of the research were also analyzed using fixed effects model, and the effect size was significant in studies number 2, 5, 6, 9, 10, 11, 12, $13,15,16,17$, and 18 .

2nd Question: Based on the meta-analysis methodology, what is the size of the effect of ICT on academic achievement (i.e. to what extent can ICT predict academic achievement)?

Table 4. Meta-analysis of the relationship between ICT and academic achievement

\begin{tabular}{|c|c|c|c|c|c|c|c|c|c|}
\hline & Z & 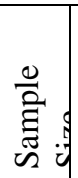 & 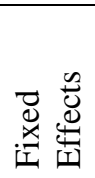 & 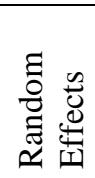 & 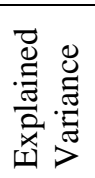 & $\begin{array}{l}2 \\
2 \\
2 \\
0\end{array}$ & 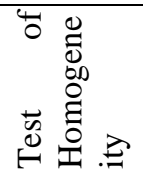 & $\mathrm{df}$ & Sig. \\
\hline $\begin{array}{l}\text { ICT and academic } \\
\text { achievement }\end{array}$ & 94 & 18 & 0.608 & 0.608 & 0.109 & $\begin{array}{l}0.383 \\
0.608 \\
\end{array}$ & $0.231 *$ & 18 & 0.072 \\
\hline
\end{tabular}

Based on the data in Table 4, the mean size of the effect of ICT (random effects) on academic achievement in the studied sample is 0.608 . Because the estimated effect size is within the confidence interval, there ICT is significantly associated with academic achievement. The homogeneity test, however, does not yield significant values. Cohen's model is used to interpret the effect size data (Table 5). 
Table 5. Interpretation of effect size data based on Cohen's model (Safiri and Sadafi, 2012)

\begin{tabular}{|c|c|c|c|}
\hline 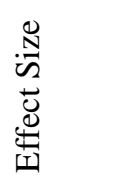 & 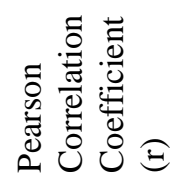 & $\begin{array}{l}0 \\
\text { n } \\
0 \overline{0} \\
\overline{0} \\
0\end{array}$ & 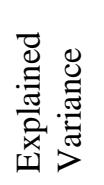 \\
\hline Small & 0.2 & 0.3 & 0.01 \\
\hline Medium & 0.3 & 0.6 & 0.09 \\
\hline Large & 0.6 & 0.9 & 0.25 \\
\hline
\end{tabular}

The results provided in Table 5 show that the calculated effect size is above the average level based on Cohen's model. Thus, there is a significant relationship between ICT and academic achievement.

\section{Discussion and Conclusion}

The purpose of the present research was to conduct a meta-analysis of the relationship between information and communications technology (ICT) and academic achievement. In the knowledge era, ICT has been very effective for the advancement of societies, especially in terms of learning and education. Indeed the mere application of ICT does not guarantee learning, but according to Clark, ICT-based methods, approaches, and techniques influence the process. This research uses a meta-analysis methodology to provide a holistic view of this relationship. Meta-analysis is a statistical approach for integrating the results of distinct studies in order to come to more accurate and valid conclusions. The effect size of individual studies (standard error of the mean, standard error, variance, lower limit, and upper limit) and fixed and random effects were used to answer the first question of the research about whether ICT has a significant effect on academic achievement. Our meta-analysis of effect sizes reported in 18 research papers showed that there is a significant relationship between ICT and academic achievement with a mean effect size of 0.608 . Since the mean effect size is within the confidence interval ( 0.383 to 0.621 ), the relationship between ICT and academic achievement is confirmed.

The second question involved the size of the effect of ICT on academic achievement. The mean effect size is almost above average (0.6) based on Cohen's interpretation. Therefore, the effect of ICT on academic achievement is medium. In other words, ICT is an important factor in learning and academic achievement. ICT is an essential aspect of the knowledge era and has been very effective in fostering and improving learning. Considering the effect size of 0.608 , we can positively claim that providing sufficient the human, financial, physical, and administrative infrastructure for ICT and using it effectively can lead to significant increase in learning. Also students will demonstrate their capabilities and skills faster and teachers will have more alternatives for teaching creatively. Moreover, ICT integrates content and information literacy, often in textual and visual forms, and produces significant learning and academic achievement. Therefore, officials in Iran's higher education system, who are faced with the challenges of globalization and the information age, must prepare students with the components of this age by effectively integrating ICT into the teaching-learning process.

\section{References}

[1] Ahmadi, M., Fallah, V., \& Mirzakhani, S. (2011). Comparing the effect of non-interactive and interactive multimedia on learning outcomes of students in primary. Iranian Journal of Information and Communications Technology in Education Sciences, 1, 4.

[2] Afkhami, M. Kamali, M., \& Shokohraveh, N. (2010). The effect of ICT on education process from the perspective of students in Yazd University. Iranian Journal of Health, 11, 1, 44-51.

[3] Arizi, H. Abedi, H., \& Ahmadi, H. (2013). Meta-analysis of the effect of psychological interventions on anxiety level. Journal of School Psychology, 2, 1, 99-118.

[4] Chaney, B. C. (2003). History, Theory, and Quality Indicators of Distance Education. Texas: Longman.

[5] Daizadeh, H., Hossienzadeh, B., \& Qaznavi, M. (2010). A review of the academic performance of secondary school students and the effect of ICT. Iranian Journal of Educational Leadership and Management, 4, 4.

[6] Farajollahi, M., \& Zarifsanai, N. (2009). ICT-based instruction in higher education. Iranian Journal of Educational Strategies, 2, 4, 27-41.

[7] Homan, H. (2008). A Practical Guide to Meta-Analysis of Empirical Research. Tehran: SAMT Publications.

[8] Hatami, J. (2006). Meta-analysis: A neglected research area Evaluation of Curriculum. Tehran: SAMT Publications.

[9] Jamali, S., Abedi, A., Aghayi, E., \& Zare, R. (2010). Comprehensive meta-analysis of emotional intelligence and mental health. Iranian Journal Psychological of Health, 4, 3, 21-31.

[10] Jamali, S., Abedi, A., Faramarzi, S., \& Aghayi, E. (2012). Meta-analysis of the efficacy of common interventions for hyperactivity and deficit disorder. Iranian Journal of Contemporary Psychology, 7, 1, 17-34.

[11] Khalkhali, A., Shakibayi, Z., \& Andosh, M. (2011). Meta-analysis of the impact of ICT on professional development of teachers. Iranian Journal of Information and Communications Technology in Education Sciences, 1, 3, 164-182.

[12] King, W. R., \& He, J. (2006). A meta-analysis of the technology acceptance model. Information \& Management, 43, 740-755.

[13] Lee, I. A. (2008). Relationship between the use of Information Technology (IT) and performances of Human Resources Management (HRM). Alliant International University, San Diego.

[14] Malekiyan, F., Narimani, M., \& Sahebjami, S. (2010). The role of cognitive and meta-cognitive strategies in motivating learners to progress in ICT-based education systems. Iranian Journal of Curriculum Planning, 25, 2, 21-38. 
[15] Mahdinejad, V., \& Amoii, M. (2011). Assessment of computer self-efficacy and attitudes toward computers in university students. Iranian Journal of Higher Education, 16, 4.

[16] Najafi, H. (2012). The pedagogical principles and theories of distance education. Iranian Journal Curriculum Planning, 9, 7, 32-41.

[17] Niyazazari, K., Behnamfar, R., \& Andi, S. (2012). The effect of using ICT on learning in elementary school students. Iranian Journal of Information and Communications Technology in Education Sciences, 2, 3, 31-43.

[18] Niyazazari, M., \& Hosseini, Z. (2012). The impact of ICT on learning math and English language in high school students. Iranian Journal of Information and Communications Technology in Education Sciences, 3, 1, 99-118.

[19] Qaznavi, M. R. (2010). The Impact of ICT on the academic achievement of high school students in Khash City. Master's Thesis, Sari Branch of Azad University.

[20] Safa, P., \& Khanak, N. (2010). The application of ICT in teaching and learning of French language. Iranian Journal of Language Studies, 2, 3, 55-63.

[21] Satari, S., \& Mohammadi, P. (2011). Relationship between use of ICT and academic success of high school students. Iranian Journal of Information and Communications Technology in Education Sciences, 1, 4.

[22] Satari, S., Namvar, Y., \& Hajnazari, Y. (2012). Familiarity with and use of information and communications technologies with respect to academic achievement of high school students. Iranian Journal of Information and Communications Technology in Education Sciences, 3, 2, 85-103.

[23] Safiri, K., \& Sadafi, Z. (2012). Mete-analysis of the research on gender and social capital. Iranian Journal of Applied Sociology, 23, 4, 37-74.

[24] Safariyan, S., Fallah, V., Mirhosseini, H. (2010). Comparison of educational modern and traditional teaching methods on learning mathematics. Iranian Journal of Information and Communications Technology in Education Sciences, 1, 2.

[25] Shekari, A. (2010). The effect of using ICT on the teaching-learning process in university academics. Iranian Journal of Higher Education Curriculum, 1, 2, 57-89.

[26] Soleymanpour, J., Khalkhali, A., \& Reayatkoonandeh, L. (2010). The impact of ICT-based teaching on sustainable learning of experimental sciences. Iranian Journal of Information and Communications Technology in Education Sciences, 1, 2, 77-91.

[27] Zameni, F., Kardan, S. (2010). Impact of using ICT on learning mathematics. Iranian Journal of Information and Communications Technology in Education Sciences, 1, 1, 23-38.

[28] Zameni, F., Nasimi, A., Rezayirad, M., \& Ghanbarpoor, M. (2011). The impact of multimedia applications on the academic achievement of students in a sociology class. Iranian Journal of Information and Communications Technology in Education Sciences, 2,2 .

[29] Zare, A. (2009). Understanding the impact of ICT on students' progress. Iranian Journal of Educational Research, 18, 3, 75-94.

[30] Zofan, S. (2007). Use of New Technologies in Education. Tehran: SAMT Publications. 